\title{
EL CONCEPTO DE MÍMESIS EN TRADUCCIÓN LITERA- RLA: ENTRE LA LIBERTAD Y EL DETERMINISMO*
}

\author{
Luis PEGENAUTE RODRÍGUEZ
}

Durante mucho tiempo se consideró la traducción un mal necesario que intentaba paliar las limitaciones que el hombre encontraba a la hora de establecer contactos con individuos pertenecientes a otras comunidades lingüísticas y con las herencias culturales legadas por aquéllos en soporte escrito. Era, por así decirlo, una manera de recordarnos lo imperfecto de nuestra condición. Esta concepción daba cuerpo a una importante paradoja, pues otorgaba a las obras literarias, en particular a las grandes obras que conforman la literatura canonizada y que supuestamente han de presentarse como modelos dignos de imitación, el dudoso honor de ser irrepetibles y, mucho menos, inimitables. Ello redundó en recurrentes e indiscriminadas comparaciones liscales entre los originales y sus traducciones para ver cuánto distaban éstos de aquéllos y denunciar así qué se había perdido en el inevitable, pero también doloroso trasvase interlingüístico. Desde esta perspectiva, no resultaba extraña la costumbre de considerar de manera aprioristica $y$, por tanto, infundada, toda obra cualitativamente superior a su traducción ${ }^{2}$.

- Este trabajo consiste en una revisión y actualización de la ponencia presentada bajo el mismo lítulo en el / Taller de Traducción e Interpretación ("La traducción a las puertas del siglo $X X \mathrm{~J}$ "), que se celebró en la Universidad de La Habana entre los días 6 y 9 de diciembre de 1994.

${ }^{1}$ Así, por ejemplo, C. Pichois y A.-M. Rousseau afirmaban: "Las traducciones directas, es decir, las realizadas directamente del original, son las que presentan mayores garantías, pero no pueden rivalizar con ël", La literatura comparada (Madrid: Gredos, 1969). p. 70. Cierto es que apuntan unas pocas "excepciones" a las que denominan "obras maestras en su propia lengua ly quel han pasado a ser obras maestras en otra lengua y otro registro" (ibid). Según ellos (pp. 70-71), tal es el caso del Poe traducido por Baudelaire y Mallarmé, las versiones de Schlegel y Tieck de Shakespeare, el Dafnis $y$ Cloe traducido al francés por Amyot y Courier, las traducciones del Amadis de Gaula de Des Essart, Las Mil y una noches de Galland y la versión que Boscán hizo de $/ /$ Cortigiano de Castiglione. Es justo decir que esta afirmación un tanto temeraria no se corresponde con $\$$ sus declaraciones de principios una páginas mis adelante, donde podemos observar una aproximación al fenómeno traductor verdaderamente "moderna". Comentan allí la necesidad de examinar la traducción desde el punto de vista del polo receptor, donde se integrará para cumplir una determinada función: “Ingenuas o cultas, feas o hermosas, buenas o malas, las traducciones pertenecen a la literatura que las acoge y se integran en su patrimonio. Juzguémoslas, pues, por la necesidad que las hizo nacer, el entusiasmo que provocaron, su popularidad, su irradiación y su influjo. 1...] Puesto que hay que estudiar la 
Tradicionalmente los originales han sido definidos como entidades inmutables, en cuya existencia no interfiere la presencia (o ausencia) de traducciones. Por el contrario, estas últimas serían accidentales y episódicas y como tales estarían condenadas a quedar caducas, a ser reemplazadas por otras, una vez que han dejado de cumplir la función que se les había destinado. La tradición religiosa occidental nos ha legado una serie de símiles o metáforas que muy bien podrían ser aplicados a la distinción entre original y traducción. El hombre se refiere muchas veces a si mismo como mortal, atestiguando de este modo su naturaleza imperfecta. Poco importa que fuera hecho a imagen y semejanza de la ligura divina, antes de la cual no había nada, sólo oscuridad. La caída del hombre, como es sabido, tuvo lugar por un exceso de engreimiento y de codicia, pero también por ingratitud. Pues bien, muchas veces los traductores (entiéndase sus obras) han sido expulsados del paraíso terrenal, del reino de la gloria, por suponer una amenaza para los verdaderos creadores y condenados no sólo a vivir una vida terrenal que poco tiene que ver con la celestial, sino, lo que es más, a que tal vida sea limitada y por lo general sólo sirva para granjearse la condena más terrible que cabe imponer a un artista: el olvido; de tal modo, que sólo son unos pocos los elegidos para alcanzar la gracia eterna, muchas veces tras haber cumplido debida pena por sus culpas en el purgatorio. mientras que la mayor parte de ellos son condenados irremediablemente a morar para siempre en el infierno de la mediocridad.

Que las traducciones tienen un carácter segundo no puede ser negado, pues lógicamente requieren la existencia de un texto escrito previamente en otra lengua, pero, como señala Etkind², no hay por qué hacer a este término

traducción en sí misma, uno se guardarả de darle una nota como en un examen. Se la vinculará a su contexto histórico, ideológico y estilístico" (pp. 190-91). Probablemente ha sido I. Even-Zohar uno de los teóricos que con mayor vehemencia ha rechazado esa concepción tradicional que consideraba a todo original necesariamente superior a su traducción y que dictaba incluso una teoría prescripitiva y normativa. del quahacer traductor sin atender a las condiciones lingüísticas, literarias, culturales, ideológicas, etc. imperantes en cada transferencia en particular: "How many times have we been torturod by the clichés of the uninitiated, voteran or novice, that translation is never equal to the original, that languages differ from one another, that culture is 'also' involved with translation procedures, that when a translation is 'exact' it tends to be 'literal' and hence loses the 'spirit' of the original, that the 'meaning' of a text means both 'content' and 'style' and so on. Not to speak of such approaches where norms are either overtly or covertly stated, i.e., where we are told how translations should look or how they should be conceived of in terms of one or another evaluative norm", Itamar Even-Zohar, "Translation Theory Today", Translation Theory and Intercultural Relations (Poetics Today, 2: 4), eds. I. EvenZohar \& Gideon Toury, (Tel Aviv: The Porter Institute for Poetics and Semiotics, 1981), pp. 2-8 (p. 2).

${ }^{2}$ E. Etkind, Un art en crise: essai de poétique de la traduction poétique, trad. W. Troubetzkoy (Lausanne: L'Age d'Homme, 1982), p.xv. 
sinónimo de secundario. Muchas veces el estigma de obras secundarias les es otorgado por su existencia limitada, ya que en su perjuicio inciden todos los cambios culturales, lingüísticos, etc. que cabe esperar encontrar en cualquier sistema literario a lo largo de su existencia. Estos cambios determinan la necesidad de suministrar a los lectores revisiones de antiguas versiones que se adapten ideológica y estéticamente a los nuevos tiempos. Generalmente, el título de original, como la propia palabra indica, se otorga a una forma de expresión particular y exclusiva de un determinado autor, aunque no deja de ser una copia de la realidad o de la realidad imaginada por él; la traducción, sin embargo, es vista como la copia de una copia, un simulacro, una imitación o interpretación de algo tangible y verdadero ${ }^{3}$. Ahora bien, aunque ciertamente constituye una reproducción de un original, cuyo único mérito muchas veces es sólo ser su predecesor en el tiempo, no por ello ha de discriminarse en favor de aquél pues, en palabras de Etkind. "de caractère reproductil sont bien tous les arts d'exécution, ceux du pianiste, de l'acteur, du metteur en scène"4.

Es importante que nos replanteemos la propia noción de originalidad. En este sentido ha sido fundamental la contribución hecha por Benjamin ya en 1923, en su famosa introducción a la versión alemana de Tableaux Parisiens, de Baudelaire, donde encontramos un ensayo recuperado más tarde por los desconstruccionistas y teóricos postestructuralistas de la traducción ${ }^{5}$. En tal ensayo, Benjamin utiliza el concepto de traducción como

"Vẻase Lawrence Venuti, "Introduction", Rethinking Translation: Discourse, Subjectivity, Ideology, ed. Lawrence Venuti (London: Routledge, 1992), p. 3.

4 Etkind, Un art en crise. p. xv. El hecho de que constituya una imitación no implica una jerarquización desfavorable en relación al original: "Un art second, certes, mais second ne veut pas dire secondaire" (ibid).

${ }^{5}$ El ensayo en cuestión era "Die Aufgabe des Öbersetzers", que Benjamin presentaba como prefacio a su traducción al alemán de Tableaux Parisiens (Heidelberg. 1923). La traducción al inglés de ese ensayo (“The Task of the Translator») apareció por primera vez en Walter Benjamin, Illuminations, ed. e intr. Hannha Harendt (New York: Harcourt, Brace and World, 1968). Ha sido reimpreso recientemente en Theories of Translation: An Antohology of Essays from Dryden to Derrida, ed. Rainer Schulte \& John Biguenet (Chicago: The University of Chicago Press, 1992), pp. 71-82. En castellano se encuentra disponible bajo el útulo de "La tarea del traductor" en Textos clásicos de teoría de la traducción, ed. Miguel Angel Vega (Madrid: Cátedra, 1994), pp. 285-98. En cuanto a su recepción por críticos posteriores, conviene tener en cuenta los siguientes trabajos: J. Derrida, "Des Tours de Babel" (1980), en Difference in Translation, ed. Joseph F. Graham (Ithaca: Cornell University Press, 1985), pp. 165-208; Paul de Man, 'Conclusions': Watter Benjamin's The Task of the Translator" (1983), en The Resistance to Theory (Minneapolis: The University of Minneapolis Press, 1986), pp. 73-105; Andrew Benjamin. Translation and the Nature of Philosophy: a New Theory of Words (London: Routledge, 1989), pp. 86-108; John Johnston, "Translation as Simulacrum", en Rethinking Translation, ed. Lawrence Venuti, pp. 42-56;. 
perpetuación de la vida del original't. Derrida, por su parte, siguiendo a Benjamin, se cuestiona la supuesta supremacía del texto extranjero. Así, en "Des Tours de Babel" afirma que tal texto no es en absoluto un original, sino que es en sí mismo una traducción, una interpretación 0 , incluso, una paráĺrasis de una idea. No seria algo cerrado o finito, sino el comienzo de una vida que será eterna mientras el texto sea traducido. Al desechar la dicotomia entre original y traducción, carece de sentido asignar a esta última una condición secundaria ${ }^{7}$. En opinión de los postestructuralistas, lo que hace original a un texto escrito en otra lengua es el hecho de que es digno de ser traducido, pero ello entraña una cierta paradoja, pues le hace depender de su traducción para lograr su canonización. Todo esto indica que el texto original (TO) no es algo autosuficiente, completo e independiente. Los postestructuralistas propugnan que lo que tradicionalmente se entendia por original es en realidad una traducción, en cuanto que deriva y depende de la percepción del autor y supone la elaboración de un significado, un concepto. El hecho traductor se convierte en una actividad que permite a un determinado texto perpetuar su vida en otro contexto, y el texto traducido adquiere el status de original en virtud de su existencia en ese nuevo contexto. En este sentido, no está de más señalar que, por ejemplo en Rusia, grandes autores como Pushkin, Dostoyevsky, Turgenev, Buni, Pasternak, etc. han desempeñado repetidamente el noble cometido de la traducción y muchos de ellos sólo se han considerado en verdad escritores una vez que sus obras han sido traducidas.

No cabo duda de que en una traducción, como acto de (re)creación que es, afloran todas las idiosincrasias personales del traductor, sus convicciones estéticas, su concepción del mundo, su interpretación de la literatura y de la obra literaria que está vertiendo en otro idioma. Ahora bien, tal y como señala Venutit aunque toda su experiencia pueda encontrar reflejo en su

"Susan Bassnett, en Comparative Literature: a Critical Introduction (London: Routledge, 1992), p. 151, emparenta esta concepción de Benjamin con la adoptada por Ezra Pound al defenderse de los ataques sufridos por su Homage to Sextas Propertias. El poeta inglés delinía la traducción como una resurrección, una vida después de la muerte. Decia asi: "there never was any question of translation, let alone literal translation. My job was tro bring a dead man to life, to present a living ligure". (Carta a A.R. Orage, abril de 1916, en D.D. Paige, ed., The Letters of Ezra Pound 1907-1916, London: Faber and Glaber, 1961. Apud Susan Bassnett ,Comparative Literature, pp. 150-51).

7 En palabras de Derrida, "I rather wished to mark the fact that every translator is in a position to speak about translation, in a place which is more than any not second or secondary. For if the structure of the original is marked by the requirement to be translated, it is that in laying down the law the original begins by indebting itself as well with regard to the translator. The original is the lirst debtor. the first petitioner; it begins by lacking and by pleading for translation" ("Des "Tours de Babel", p. 184).

"Introduction," Rethinking Translation, p. 4. 
traducción, en términos de originalidad a su trabajo no se le asigna la misma posición jerárquica que la copia hecha por el autor, la "copia autorizada". Ello es debido a que al traductor se le exige su autoinmolación; se le pide que desaparezca todo vestigio de quehacer traductor en la versión que él está presentando, de tal manera que el receptor se encuentre ante un espejismo, una ilusión de la imaginación: un autor extranjero escribe en nuestro propio idioma. De este modo, muchos traductores anhelan el anonimato para así conseguir la fama, considerando que si no se hace referencia a su persona. si no se ve la huella de una pluma intermedia, es porque la traducción está bien hecha.

Toda obra literaria constituye un autorretrato (consciente o inconsciente) del autor; por ello, el traductor se ha de sentir moralmente obligado a transmitir la individualidad artística de aquél y la unicidad de su estilo, abstenióndose de matizar su versión con el suyo, ya que, de lo contrario, correri el riesgo de convertirla en su propio retrato. Ciertamente es éste un duro cometido: sacrificarse absolutamente, de tal lorma que toda huella de su labor desaparezca. De todos modos, no cabe duda de que la traducción (literaria) de una obra literaria sólo será posible si ésta se recrea a partir de las leyes imperantes on otros sistemas lingüísticos, culturales, ideológicos y estéticos. El objetivo no es crear una mera copia, sino un texto que conforme en su totalidad un equivalente. Resulta inevitable, por tanto, que original y traducción se distingan como consecuencia de las exigencias de las diferentes lenguas y tradiciones culturales. Debemos tener también en cuenta que, debido al carácter intrínseco de la traducción como fenónemo de reescritura enmarcado entre dos polos, la libertad de acción se ve enormemente restringida. Precisamente por esto, críticos como Savory consideran que el trabajo del traductor merece muchas veces más respeto y consideración que el del propio autor "original". En este sentido, dicho autor afirmaba hace ya treinta años:

The translator's task is much harder than that of the original author. When the latter seeks a word with which to express a thought or describe an experience, he has available many words in his own language, and can without great difficulty or delay choose the one that suits him best and pleases him most. The translator of the word thus chosen has to decide on the nearest equivalent, taking into consideration the probable thoughts of the author, the probable thoughts of the author's readers and of his own readers, and the period of history in which the atthor lived".

Se suele tener la convicción de que el texto traducido ha de parecer original; para ello se ha de lograr una transparencia, una fluidez que sólo resulta posible tras la aplicación constante de una serie de estrategias de trasvase, cuya finalidad última es muchas veces despojar a la obra "origi-

"T. H. Savory, The Art of Translation (London: Jonatan Cape, 1968), p. 26. 
nal" de todo lo que pudiera parecer exótico o heterodoxo, tanto en el ámbito estético como el ideológico. En lo que respecta al primero, vemos que, en términos generales, prescindiendo incluso de los condicionantes impuestos por la poética imperante en todo sistema literario en un momento dado de su evolución, se suele tender a una normalización lingüística y estilística, evitando todos los aspectos que no resulten corrientes y nos hagan reflexionar sobre la materialidad del lenguaje ${ }^{10}$. En lo que concierne al factor ideológico, apreciamos que el traductor se encuentra en una posición privilegiada para manipular, si lo considera conveniente, el T0 y adaptarlo al universo cultural del sistema receptor, sea para salvaguardar los valores éticos, morales, políticos, religiosos o de cualquier otro tipo sobre los que éste se sustenta o simplemente para no transgredirlos. En todo caso, de ello depende en gran medida la canonización de su traducción y su inclusión en lo que se considera literatura oficial.

Tal y como señala Lefevere, la cuestión de la canonización de las obras literarias (y también de las versiones extranjeras resultantes de su reescritura) ha de ser considerada en conjunción con una serie de factores determinantes, a saber, el tipo de ideologia, poética, grado de institucionalización, censura, etc. del sistema cultural en cuestión ${ }^{11}$. Tanto la selección del material que va a a ser sometido a un trasvase interlingüístico como el propio proceso traductor que va a tener lugar, varian en función de la mayor o menor influencia de tales cuestiones. Su importancia no acaba aqui, pues también condicionan su posterior recepción y la atribución, aunque sea temporal, de un determinado status, que se verá modilicado diacrónicamente conforme los propios condicionantes vayan variando su naturaleza.

Como consecuencia de los comportamientos correctores antes descritos, muchos de los rasgos más personales de algunos escritores, que en definitiva son los que constituyen sus idiolectos particulares, son "suaviza-

10 Venuti señala: "Fluent translation strategies are implemented with varying degrees of success today, they require a laborious effort of revision and much stylistic refinement, and they are even occasionally applied to foreign texts that put to work more discontinuous discourses. Yet whatever their effectiveness, such strategies do take a characteristic form: they pursue linear syntax, univocal meaning or controlled ambiguity, current usage, linguistic consistency, conversational thythms; they eschew unidiomatic constructions, polysemy, archaism, jargon, abrupt shifts in tone or diction, pronounced rhythmic regularity or sound repetitions -any texiual effect, any play of the signifier, which calls attention to the materiality of language, to words as words, their opacity, their resistance to emphatic response and interpretive mastery," "Introduction," Rethinking Translation, p. 4. Venutti pone de manifiesto en The Translator's Invisibility: a History of Translation (London, Routledge. 1995) que. desde el siglo XVII, la tónica general ha sido celebrar aquellas versiones fluidas que presentan la apariencia de obras "originales".

11 Andre Lefevere, Translation, Rewriting and the Manipulation of Literary Fame (London: Routledge, 1999. Véase en particular el cap. II, "The system: patronage" (pp. 11-25). 
dos" o convenientemente "adaptados" en el trasvase interlingüístico. El traductor sólo puede mantener las características idiosincráticas del autor si cl sistema meta lo permite, tanto en su vertiente lingüística, como literaria y cultural. Para cumplir su cometido sólo podrá valerse de su percepción de lo que Poggioli denomina literary mimesis, pues resulta imposible proponer unas pautas aplicables a todas las realizaciones concreta ${ }^{12}$. El componente lingüístico se encuentra inexorablemente unido al factor cultural y estético y resulta imposible formular una teoría que cubra todas las situaciones posibles. El quehacer de los traductores coetáneos, a pesar de la variedad intrínseca a todo acto de (re)creación personal, refleja a menudo similitudes relevantes como consecuencia de los dictámenes de la estética imperante en ese momento ${ }^{13}$. No es extraño que las traducciones configuren una referencia inevitable en el campo de la Literatura Comparada ya que nunca constituyen actuaciones aisladas o caprichosas, sino que son reflejo de tradiciones literarias: When looking at the raw material which the translator molds and reshapes into a work of his own, the critic finds a set of concrete problems that may and must be submitted to detailed analysis and elaborate judgement. Here the terms of comparison are not only the language of the original work and the language of the translated one, but even more the two literary traditions involved ${ }^{t+}$.

En todo caso, a pesar de la normalización a la que son sometidas numerosas obras durante su trasvase, no hemos de desdeñar el carácter interpretativo que supone todo acto traductor. La traducción, como acto individualizado y personal que es, permite establecer incontables variantes de un mismo texto. La disimilitud de estas variantes prueba que numerosos textos literarios admiten diferentes interpretaciones: "The same translator may treat different texts in different ways, and the same text may be treated differently by different translators" 15 .

El concepto de traducción como (re)creación está intimamente ligado a las cuestiones de libertad y determinismo. Cuando emprendemos la lectura

12 Renato Poggioli, "'The Added Artificer, " On Translation, ed. Reuben Bower (Cambridge, Mass.: Harvard University Press), pp. 137-47.

${ }_{13}$ Tal y como señalan Pichois y Rousseau, no podemos juzgar estas traducciones por los patroties imperantes hoy en dia: "La estética clásica define desde 1640 las reglas de la composición, el respeto debido a la decencia, la necesidad de verosimilitud, el gusto por una lengua noble -por tanto empobrecida- y por un estilo elevado; todo ello hacía imprescindibles esos disfraces y mutilaciones. Condenar a los traductores que se sometieron a ello, equivaldria a confesar una radical incomprensión do lo que fue la época clásica, que, en Francia, duró dos siglos. [... I Entonces se comprende mejor la ingrata tarea de los traductores franceses y de sus infinitos escrüpulos, allí donde nosotros, incautamente, sólo veríamos ausencia de escrúpulos," La literatura comparada, p. 74.

it Poggioli, "The Added Artilicer", p. 143.

is Henry H. Schogt, Linguistics, Literary Analysis and Literary Translation (Toronto University Press, 1988), p. 105. 
de una obra, hacemos uso de nuestros inventarios lingüísticos y experiencia extralingüística, es decir, nuestro conocimiento del mundo. Ambos aspectos differen de persona a persona y, por consiguiente, la percepción e interpretación del texto nunca será la misma. Esto ha dado lugar a la consideración en la crítica moderna de que sin lector no hay texto16. Tal supuesto plantea cuestiones de trascendental importancia en el campo de la traducción literaria. Si se enfatiza el aspecto interpretativo de la traducción, carece de sentido cuestionarse cuál es la verdadera identidad del TO y obvia toda discusión sobre la calidad de las traducciones, ya que sólo es posible comparar interpretaciones, y no hay nada más subjetivo y parcial que esto, pues generalmente se consideran mejores las interpretaciones que más se aproximan a las propias. En términos generales, se suele subrayar la necesidad de actuar con suma cautela, estableciendo una serie de límites a la libertad creativa del traductor, de forma que se asegure al autor original y su texto el respeto que merecen. Ello quiere decir que resulta deseable asumir un compromiso entre la libertad de acción que debe existir en todo acto (re)creativo y el determinismo resultante del hecho de que existe un TO que precede a su traducción en el tiempo y que sirve de base para su creación.

${ }^{I r}$ Así, por ejemplo, W. Iser, defensor junto a H.R. Jauss y otros de lo que se ha dado en llamar teoria de la recepción, caracteriza la interacción entre lector y texto en términos de una dialéctica continua: "The reader must be made to feel for himself the new meaning of the novel. To do this, he must actively participale in bringing out the meaning and this participation is an essential precondition for

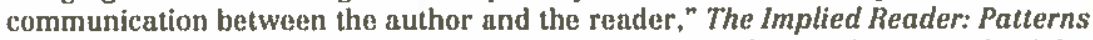
of Communication in Prose Fiction from Bunyan to Beckett (Baltimore: The John Hopkins University Press, 1974), p. xii. A postular que el lector reorganiza djalécticamente los segmentos textuales, se invalida el modelo unidireccional de lectura, se asume que comprensión y creación son términos sinónimos y se subraya su papel fundamental a la hora de dar vida a un texto: "Fictional texts constitute their own objects and do not copy something already in existence. For this reason they cannot have the total determinacy of real objects, and indeed, it is the etements of indeterminacy that enable the text to 'communicate' with the reader, in the sense that they induce him to participate both in the production and the comprehension of the work's intention," The Act of Reading: A Theory of Aesthetic Response (Baltimore: The John Hopkins University Press, 1978), p. 24. 